\title{
Association between mobile phone use and depressed mood in Japanese adolescents: a cross-sectional study
}

\author{
Kayoko Ikeda $\cdot$ Kazutoshi Nakamura
}

Received: 9 August 2013/ Accepted: 28 November 2013/Published online: 18 December 2013

(C) The Japanese Society for Hygiene 2013

\begin{abstract}
Objectives Mobile phones are commonly used by adolescents. The aim of this study was to clarify associations between duration of mobile phone use and psychological mood in high school students.

Methods This cross-sectional study included 2,785 high school students in Niigata, Japan. A self-administered questionnaire was used to elicit information on sex, school year, hours of mobile phone use, psychological mood status, and possible confounders. Psychological mood outcomes were evaluated with the Mood Inventory, developed and validated in 1994, which includes five subcomponents with total scores ranging from 8 to 32 (higher score indicates stronger feeling): "Tension and excitement," "Refreshing mood," "Fatigue," "Depressed mood," and "Anxious mood." Analysis of covariance with Bonferroni's multiple comparison was used to compare mean values among quartiles of hours of mobile phone use.

Results Among the respondents, mean mobile phone use per week was 24 (median 18) h. Long-duration mobile phone use was associated with female students, no participation in sports club activities, early mobile phone use, and fewer hours spent sleeping (all $P<0.001$ ). Overall associations between hours of mobile phone use and total scores were significant for "Depressed mood" $(P$ for
\end{abstract}

\section{K. Ikeda $(\bowtie)$}

Department of Nursing, Niigata Seiryo University School

Corporation, Niigata Seiryo Educational Institute,

1-5939 Suido-cho, Chuo-ku, Niigata 951-8121, Japan

e-mail: ikeda@n-seiryo.ac.jp

\section{K. Nakamura}

Division of Preventive Medicine, Niigata University Graduate School of Medical and Dental Sciences, 1-757 Asahimachi-dori, Chuo-ku, Niigata 951-8510, Japan trend $=0.005)$, "Tension and excitement" ( $P$ for trend $<0.001)$, and "Fatigue" ( $P$ for trend $<0.001)$. Total scores for "Depressed mood," "Tension and excitement," and "Fatigue" of the fourth quartile ( $\geq 33 \mathrm{~h} /$ week) of mobile phone use were significantly higher than for other quartiles (all $P<0.05$ ).

Conclusions Increased duration of mobile phone use is associated with unfavorable psychological mood, in particular, a depressed mood. Decreasing mobile phone use may help maintain appropriate mental health in very longduration users.

Keywords Adolescent - Cellular phone . Cross-sectional studies $\cdot$ Mood disorders

\section{Introduction}

Mobile phones are commonly used in Japan. The Ministry of Public Management reported that $94.5 \%$ of Japanese households have them [1]. Among the younger generation, $47.8 \%$ of junior high and $95.6 \%$ of high school students have mobile phones [2]. The widespread use of mobile phone use among today's youth is partly because mobile phones are multi-functional, with phone, e-mail, and Internet applications.

This situation has raised concerns about the adverse effects of excessive mobile phone use on the physical and mental health of adolescents. Excessive mobile phone use is associated with poor perceived health, including tiredness, stress, headaches, and concentration difficulties [3, 4]. Various studies have also examined the effects of mobile phone use on adolescent psychological status. Tayama [5] suggested that excessive mobile phone use is associated with poor psychological status in adolescents, such as 
anxiety and depression. Yen et al. [6] showed that adolescents with depression were more likely to have problematic mobile phone use behavior. These studies highlight the need to examine psychological impairment derived from mobile phone use in order to develop measures to maintain normal mental health in the adolescent population.

Japanese adolescents use mobile phones not only as phones, but also for e-mailing and browsing the Internet [5], resulting in an extended use of mobile phones by some adolescents. Kamibeppu and Sugiura [7] showed that Japanese adolescents use mobile phones more frequently for e-mailing than as a phone and that greater e-mail use was associated with increased psychological instability. Additionally, the various uses of mobile phones may make adolescents unaware of the passage of time. In fact, Internet addiction in adolescents is considered to be a grave problem and to be associated with mobile phone use [5, 8].

We hypothesized that the duration of mobile phone use is an important determinant of psychological health in adolescents; however, to our knowledge, few epidemiological studies have tested this hypothesis. The aim of this study was to assess associations between the duration of mobile phone use and psychological mood in high school students, with a focus on depression. Our findings should aid in the formulation of efficient efforts to regulate student mobile phone use by school health professionals in order to maintain the mental health of students.

\section{Materials and methods}

\section{Participants and procedure}

This cross-sectional study included students from seven high schools (six public and one private schools) in Niigata Prefecture, Japan, where there are 92 public and 15 private high schools. As a prefecture-wide survey was not allowed, we approached ten accessible high schools directly, with the invitation to participate in our study. Seven schools agreed to participate, including five high schools [student enrolment $n=952$ (private school), 997, 929, 759, and 491, respectively] in the Kaetsu area (northern Niigata, including Niigata City, the capital of this prefecture), one high school $(n=471)$ in the Chuetsu area (central Niigata), and one high school $(n=587)$ in the Joetsu area (southern Niigata). Among the seven high schools (total enrolment 5,186 students), one high school approved the participation of all students, whereas six high schools approved the participation of all but third-year students; hence, the target population was limited to 2,929 students. We distributed anonymous self-administered questionnaires to these 2,929 students during classroom hours between October 2011 and March 2012 after their homeroom teacher explained the purpose of the study. It was then emphasized that participation in the study was completely voluntary. Students returned the questionnaires in sealed envelopes to ensure confidentiality. Neither the questionnaires nor the envelopes included any means of identification. Of the 2,929 students, 2,891 (98.7 \%) agreed to participate in the survey. After excluding 106 questionnaires with incomplete information on demographic characteristics or mobile phone use, data from the 2,698 $(93.3 \%)$ completed questionnaires were analyzed. The protocol for this study was approved by the Ethics Committee of Niigata Seiryo University.

\section{Questionnaire}

The questionnaire elicited information on sex, school year, possession of mobile phone, time of the first mobile phone use $(1=$ junior high school or earlier; $2=$ high school $)$, hours of mobile phone use, hours spent sleeping, participation in school sports club activities, and psychological mood status. Regarding mobile phone use, we asked students to report the total number of hours that they used their mobile phone for phoning, e-mailing, and browsing the Internet, separately by weekdays and weekends during a typical week. We did not differentiate between these three applications in terms of duration of use of mobile phone, given the anticipated difficulty. Number of hours spent sleeping was also reported.

Mood status during the previous week was evaluated using the Mood Inventory developed and validated by Sakano et al. [9] in 1994. The Mood Inventory is a tool to assess various aspects of a person's subjective psychological mood, and a validation study has been performed in Japanese subjects, including teenagers [9]. The Mood Inventory describes five mood subcomponents: "Tension and excitement," "Refreshing mood," "Fatigue," "Depressed mood," and "Anxious mood." Each subcomponent consists of eight statements, such as "Kimochi-ga-meitteiru (I feel gloomy)," "Kibun-ga-shizunde-yuutsudearu (I feel low)," "Mijimeda (I feel miserable)," "Gakkarisiteiru (I am discouraged)," "Ki-ga-omoi (I feel heavy)," "Tsurai (I feel painful)," "Munasii (I feel melancholy)," and "Hitorikiri-no-youdesamishii (I feel lonely)," for "Depressed mood." Responses were expressed numerically, with $1=$ strongly disagree, $2=$ disagree, $3=$ agree , and $4=$ strongly agree. The eight item scores were summed for total subcomponent scores ranging from 8 to 32, with higher scores indicating stronger feelings for that subcomponent. Cronbach's alpha coefficients in our samples were 0.839 for "Tension and excitement," 0.775 for "Refreshing mood," 0.849 for "Fatigue," 0.901 for "Depressed mood," and 0.855 for "Anxious mood," which are satisfactorily high. 
Table 1 Characteristics of the 2,698 participants stratified by quartiles of hours of mobile phone use per week (weekdays and weekends)

\begin{tabular}{|c|c|c|c|c|c|}
\hline \multirow[t]{2}{*}{ Participants } & \multicolumn{4}{|c|}{ Hours of mobile phone use per week } & \multirow{2}{*}{$\begin{array}{l}P \text { for } \\
\text { trend }^{\text {a }}\end{array}$} \\
\hline & $\begin{array}{l}\text { Quartile } 1:<10 \mathrm{~h} / \\
\text { week }(N=741)\end{array}$ & $\begin{array}{l}\text { Quartile 2: } 10-18 \mathrm{~h} / \\
\text { week }(N=622)\end{array}$ & $\begin{array}{l}\text { Quartile 3: } 19-32 \mathrm{~h} / \\
\text { week }(N=691)\end{array}$ & $\begin{array}{l}\text { Quartile } 4: \geq 33 \mathrm{~h} / \\
\text { week }(N=644)\end{array}$ & \\
\hline Females $(\%)$ & 49.4 & 63.7 & 64.4 & 74.5 & $<0.001$ \\
\hline First-year students (\%) & 46.7 & 46.6 & 46.2 & 42.0 & 0.373 \\
\hline Participation in sports club (\%) & 43.2 & 45.4 & 42.5 & 32.1 & $<0.001$ \\
\hline $\begin{array}{l}\text { Mobile phone users since junior } \\
\text { high school }(\%)\end{array}$ & 34.5 & 44.3 & 51.4 & 60.0 & $<0.001$ \\
\hline Hours spent sleeping ${ }^{\mathrm{b}}$ & $6.3(1.0)$ & $6.3(0.9)$ & $6.2(1.0)$ & $6.1(1.0)$ & $<0.001$ \\
\hline
\end{tabular}

a Tested by simple logistic regression analysis

${ }^{\mathrm{b}}$ Presented as the mean with the standard deviation (SD) in parenthesis. $P$ for trend tested by simple regression analysis

\section{Statistical analysis}

The five subcomponent scores of the Mood Inventory had approximately normal distributions. Analysis of covariance (ANCOVA) was used to compare mean values among quartiles of total hours of mobile phone use with Bonferroni's multiple comparison for any two groups. Trend tests were conducted using linear regression analysis for continuous outcomes and logistic regression analysis for dichotomous outcomes. Multivariate analysis was performed with adjustment for possible confounding factors, such as sex, school year (continuous variable), participation in school sports club activities (dichotomous variable), time of the first mobile phone use (dichotomous variable), number of hours sleeping (continuous variable), and seven schools (six dummy variables). SPSS ver. 21 was used for the statistical tests (SPSS Inc., Chicago, IL). $P<0.05$ was to be considered statistically significant.

\section{Results}

The 2,785 study participants included 1,735 (62.3\%) females and $1,050(37.7 \%)$ males, of whom 1,279 $(45.9 \%), 1,361(48.9 \%)$, and $145(5.2 \%)$ were first-, second-, and third-year students, respectively. Of the 2,765 $(99.3 \%)$ students who had mobile phones, 1,301 (47.2 \%) had used a mobile phone since junior high school, and $1,454(52.8 \%)$ began using one after entering high school. Students who did not have mobile phones were classified as having zero hours of mobile phone use. Mean hours of mobile phone use per week and per weekday were 24 (median 18) h and 15 (median 10) h, respectively. The purposes of mobile phone use included e-mail (94.4\%), telephone $(66.7 \%)$, and Internet $(64.8 \%)$.

Participant characteristics, such as sex, grade, participation in school sports club activities, mobile phone use, and number of hours spent sleeping, stratified by quartiles of hours of mobile phone use are given in Table 1. Female sex, no participation in sports club activities, and early mobile phone use were significantly associated with longer duration of mobile phone use.

The relationship between hours of mobile phone use per week (including weekdays and weekends) and total subcomponent scores of the Mood Inventory are given in Table 2. The number of hours of mobile phone use was significantly associated with scores for "Tension and excitement," "Fatigue," and "Depressed mood," with scores of the fourth quartile being significantly higher than those of other quartiles. The association between number of hours of mobile phone use and "Anxious mood" showed borderline significance $(P$ for trend $=0.097$ ). The relationship between quartiles of hours of mobile phone use during the previous 5 weekdays and total subcomponent scores of the Mood Inventory are shown in Table 3. The results were similar to those shown in Table 2, with scores of the fourth quartile being significantly higher than those for other quartiles for "Tension and excitement," "Fatigue," and "Depressed mood."

Subgroup association analyses were conducted to explore the modifiable effects of sex and Internet use. Table 4 shows an association between mobile phone use in hours per week and the Mood Inventory scores stratified by sex. In males, mobile phone use in hours were significantly associated with scores for "Tension and excitement," "Fatigue," "Depressed mood," and "Anxious mood," with scores of the fourth quartile being significantly higher than those of other quartiles. In contrast, no such association was found in females, although mobile phone use in hours tended to be associated with "Depressed mood" $(P=0.075)$. Table 5 shows the same association analysis stratified by Internet use. In non-Internet-users, there were no significant associations between mobile phone use in hours and any scores, whereas findings in Internet users were similar to those of the overall analysis. 
Table 2 Mean scores of the Mood Inventory subcomponents according to quartiles of hours of mobile phone use per week (weekdays and weekends)

\begin{tabular}{|c|c|c|c|c|c|c|c|}
\hline \multirow{2}{*}{$\begin{array}{l}\text { Mood Inventory } \\
\text { subcomponents }\end{array}$} & \multicolumn{4}{|c|}{ Hours of Mobile phone use per week } & \multirow{2}{*}{$\begin{array}{l}P \text { for } \\
\text { trend }^{\text {a }}\end{array}$} & \multirow{2}{*}{$\begin{array}{l}P \text { values }^{\mathrm{b}} \\
\text { (ANCOVA) }\end{array}$} & \multirow{2}{*}{$\begin{array}{l}\text { Bonferroni's multiple comparison } \\
(P<0.05)\end{array}$} \\
\hline & $\begin{array}{l}\text { Quartile 1: } \\
<10 \mathrm{~h} / \\
\text { week }\end{array}$ & $\begin{array}{l}\text { Quartile 2: } \\
\text { 10-18 h/ } \\
\text { week }\end{array}$ & $\begin{array}{l}\text { Quartile 3: } \\
\text { 19-32 h/ } \\
\text { week }\end{array}$ & $\begin{array}{l}\text { Quartile 4: } \\
\geq 33 \mathrm{~h} / \text { week }\end{array}$ & & & \\
\hline $\begin{array}{r}\text { Tension and } \\
\text { excitement }\end{array}$ & $13.8(4.1)$ & $13.8(4.0)$ & $14.0(3.9)$ & $14.6(4.0)$ & $<0.001$ & $<0.001$ & $\begin{array}{l}\text { Quartile } 1 \text { vs. quartile } 4 \text {; quartile } 2 \text { vs } \\
\text { quartile } 4\end{array}$ \\
\hline Refreshing mood & $13.9(2.8)$ & $13.9(2.9)$ & $14.0(2.8)$ & $13.9(2.7)$ & 0.567 & 0.878 & - \\
\hline Fatigue & $15.4(4.0)$ & $15.8(3.8)$ & $15.9(3.7)$ & $16.6(4.0)$ & $<0.001$ & $<0.001$ & Quartile 1 vs. quartile 4 \\
\hline Depressed mood & $15.4(5.2)$ & $15.5(5.1)$ & $15.3(4.7)$ & $16.5(5.0)$ & $<0.009$ & $<0.002$ & $\begin{array}{c}\text { Quartile } 1 \text { vs. quartile } 4 \text {; quartile } 2 \text { vs } \\
\text { quartile } 4 \text {; quartile } 3 \text { vs. quartile } 4\end{array}$ \\
\hline Anxious mood & $17.5(5.2)$ & $17.4(4.8)$ & $17.5(4.8)$ & $18.1(4.6)$ & 0.097 & 0.147 & - \\
\hline
\end{tabular}

Data are presented as the mean with the SD in parenthesis

${ }^{a}$ Tested by multiple regression analysis, adjusted for sex, school year, participation in sports club activities, mobile phone use experience, hours spent sleeping, and schools

b Tested by analysis of covariance (ANCOVA), adjusted for sex, school year, participation in sports club activities, mobile phone use experience, number of hours spent sleeping, and school

Table 3 Mean scores of Mood Inventory subcomponents according to quartiles of hours of mobile phone use in five weekdays

\begin{tabular}{|c|c|c|c|c|c|c|c|}
\hline \multirow{2}{*}{$\begin{array}{l}\text { Mood Inventory } \\
\text { subcomponents }\end{array}$} & \multicolumn{4}{|c|}{ Hours of mobile phone use in five weekdays } & \multirow{2}{*}{$\begin{array}{l}P \text { for } \\
\text { trend }^{\mathrm{a}}\end{array}$} & \multirow{2}{*}{$\begin{array}{l}P \text { values }{ }^{\mathrm{b}} \\
(\mathrm{ANCOVA})\end{array}$} & \multirow{2}{*}{$\begin{array}{l}\text { Bonferroni's multiple } \\
\text { comparison }(P<0.05)\end{array}$} \\
\hline & $\begin{array}{l}\text { Quartile 1: } \\
<6 \mathrm{~h} / 5 \text { days }\end{array}$ & $\begin{array}{l}\text { Quartile 2: } \\
6-10 \mathrm{~h} / 5 \text { days }\end{array}$ & $\begin{array}{l}\text { Quartile 3: } \\
11-20 \mathrm{~h} / 5 \text { days }\end{array}$ & $\begin{array}{l}\text { Quartile } 4 \text { : } \\
\geq 21 \mathrm{~h} / 5 \text { days }\end{array}$ & & & \\
\hline $\begin{array}{r}\text { Tension and } \\
\text { excitement }\end{array}$ & $13.8(4.1)$ & $14.0(3.9)$ & $14.0(3.9)$ & $14.7(4.0)$ & $<0.001$ & $<0.002$ & Quartile 1 vs. quartile 4 \\
\hline Refreshing mood & $13.9(2.8)$ & $13.9(2.9)$ & $13.9(2.7)$ & $14.0(2.8)$ & 0.616 & 0.947 & - \\
\hline Fatigue & $15.4(3.9)$ & $16.0(3.8)$ & $16.0(3.8)$ & $16.5(3.9)$ & $<0.001$ & $<0.001$ & $\begin{array}{l}\text { Quartile } 1 \text { vs. quartile } 2 ; \\
\text { quartile } 1 \text { vs. quartile } 4\end{array}$ \\
\hline Depressed mood & $15.3(5.1)$ & $15.7(5.1)$ & $15.5(4.7)$ & $16.4(5.0)$ & $<0.018$ & $<0.007$ & $\begin{array}{r}\text { Quartile } 1 \text { vs. quartile } 4 ; \\
\text { quartile } 3 \text { vs. quartile } 4\end{array}$ \\
\hline Anxious mood & $17.4(5.1)$ & $17.7(4.9)$ & $17.6(4.9)$ & $18.0(4.5)$ & 0.212 & 0.454 & - \\
\hline
\end{tabular}

Data are presented as the mean with the SD in parenthesis

${ }^{a}$ Tested by multiple regression analysis, adjusted for sex, school year, participation in sports club activities, mobile phone use experience, hours spent sleeping, and schools

b Tested by analysis of covariance, adjusted for sex, school year, participation in sports club activities, mobile phone use experience, hours spent sleeping, and schools

\section{Discussion}

The most interesting finding of this study was the relationship between mobile phone use and depressed mood, which is consistent with similar findings reported by other researchers. Sánchez-Martínez and Otero [8] reported that Spanish high school students with intensive mobile phone use (defined as using a mobile phone four or more times per day or a monthly bill of at least US \$43) had a higher prevalence of depressive symptoms. Koivusilta et al. [10] studied 12- to 18-year-old Finns and reported that depressed participants had significantly longer mobile phone use. Augner and Hacker [11] also reported a significant association between problematic mobile phone use and depressive behaviors in Austrian young adults. These European prevalence studies suggest an association between the extent of mobile phone use and depressive symptoms, although depressive symptoms in these studies were evaluated with self-reported questionnaires. All of these reports support our finding of a relationship between duration of mobile phone use and depression.

Our subgroup analyses demonstrated the lack of association between long-duration mobile phone use without Internet use and depressed mood, suggesting that heavy users of mobile phones who use the Internet (e.g., browsing, on-line chatting), or both e-mail and Internet, are 
Table 4 Mean scores of Mood Inventory subcomponents according to overall quartiles of hours of mobile phone use per week stratified by sex

\begin{tabular}{|c|c|c|c|c|c|c|c|}
\hline \multirow{2}{*}{$\begin{array}{l}\text { Mood Inventory } \\
\text { subcomponents }\end{array}$} & \multicolumn{4}{|c|}{ Hours of mobile phone use per week } & \multirow{2}{*}{$\begin{array}{l}P \text { for } \\
\text { trend }^{\mathrm{a}}\end{array}$} & \multirow{2}{*}{$\begin{array}{l}P \text { values }^{\mathrm{b}} \\
(\text { ANCOVA) }\end{array}$} & \multirow{2}{*}{$\begin{array}{l}\text { Bonferroni's multiple comparison } \\
(P<0.05)\end{array}$} \\
\hline & $\begin{array}{l}\text { Quartile 1: } \\
<10 \mathrm{~h} / \\
\text { week }\end{array}$ & $\begin{array}{l}\text { Quartile 2: } \\
10-18 \mathrm{~h} / \\
\text { week }\end{array}$ & $\begin{array}{l}\text { Quartile 3: } \\
\text { 19-32 h/ } \\
\text { week }\end{array}$ & $\begin{array}{l}\text { Quartile 4: } \\
\geq 33 \text { h/week }\end{array}$ & & & \\
\hline Female & $N=366$ & $N=396$ & $N=445$ & $N=480$ & & & \\
\hline $\begin{array}{l}\text { Tension and } \\
\text { excitement }\end{array}$ & $13.7(3.9)$ & $13.8(3.8)$ & $13.8(3.8)$ & $14.3(3.8)$ & 0.150 & 0.336 & - \\
\hline $\begin{array}{l}\text { Refreshing } \\
\text { mood }\end{array}$ & $14.0(2.8)$ & $14.0(2.9)$ & $14.0(2.8)$ & $13.9(2.8)$ & 0.440 & 0.842 & - \\
\hline Fatigue & $15.6(4.0)$ & $15.9(3.8)$ & $16.0(3.7)$ & $16.6(3.9)$ & $<0.028$ & 0.156 & - \\
\hline $\begin{array}{l}\text { Depressed } \\
\text { mood }\end{array}$ & $15.5(4.9)$ & $15.9(5.0)$ & $15.4(4.6)$ & $16.4(4.9)$ & 0.257 & 0.075 & - \\
\hline Anxious mood & $17.5(5.0)$ & $17.9(4.7)$ & $17.5(4.7)$ & $18.0(4.5)$ & 0.592 & 0.557 & - \\
\hline Male & $N=375$ & $N=226$ & $N=246$ & $N=164$ & & & \\
\hline $\begin{array}{l}\text { Tension and } \\
\text { excitement }\end{array}$ & $14.0(4.4)$ & $13.8(4.2)$ & $14.4(4.1)$ & $15.6(4.3)$ & $<0.001$ & $<0.001$ & $\begin{array}{c}\text { Quartile } 1 \text { vs. quartile } 4 \text {; quartile } 2 \text { vs } \\
\text { quartile } 4 \text {; quartile } 3 \text { vs. quartile } 4\end{array}$ \\
\hline $\begin{array}{l}\text { Refreshing } \\
\text { mood }\end{array}$ & $13.8(2.8)$ & $13.8(2.8)$ & $13.9(2.7)$ & $13.9(2.5)$ & 0.841 & 0.995 & - \\
\hline Fatigue & $15.2(4.1)$ & $15.6(3.7)$ & $15.6(3.7)$ & $16.5(4.1)$ & $<0.001$ & $<0.004$ & Quartile 1 vs. quartile 4 \\
\hline $\begin{array}{l}\text { Depressed } \\
\text { mood }\end{array}$ & $15.3(5.4)$ & $14.8(5.1)$ & $15.2(4.8)$ & $16.8(5.2)$ & $<0.007$ & $<0.002$ & $\begin{array}{c}\text { Quartile } 1 \text { vs. quartile } 4 \text {; quartile } 2 \text { vs } \\
\text { quartile } 4 \text {; quartile } 3 \text { vs. quartile } 4\end{array}$ \\
\hline Anxious mood & $17.4(5.3)$ & $16.5(4.9)$ & $17.5(5.0)$ & $18.4(4.8)$ & $<0.046$ & $<0.006$ & Quartile 2 vs. quartile 4 \\
\hline
\end{tabular}

Data are presented as the mean with the SD in parenthesis

${ }^{a}$ Tested by multiple regression analysis, adjusted for school year, participation in sports club activities, mobile phone use experience, hours spent sleeping, and schools

b Tested by ANCOVA, adjusted for school year, participation in sports club activities, mobile phone use experience, number of hours spent sleeping, and schools

susceptible to mood disorders. Use of the Internet via the mobile phone requires even less communication than e-mail or telephone and may be a key factor related to mobile phone addiction. By contrast, long-duration use of e-mail or telephone alone may not necessarily represent an issue, possibly because a mobile phone is considered by adolescents to be an important communication tool.

An association between hours of mobile phone use and depressed mood was more clearly observed in our male respondents than in our female respondents. This may be explained, at least in part, by the tendency that males are more addicted to the Internet [12]. In addition, male students may communicate with their friends more poorly than female students, as suggested by an earlier report describing loneliness to be associated with Japanese male adolescents with a mobile phone e-mail addition [13]. Thus, more care should be given to male adolescents with long-duration mobile phone use.

Few studies have focused on the duration of mobile phone use and depressive symptoms. In addressing this issue, we found that among our respondents the highest quartile of mobile phone use was associated with depressed mood. This group used their mobile phones for many hours ( $\geq 33 \mathrm{~h} /$ week or $\geq 4.7 \mathrm{~h} /$ day) and, as a result, had a significantly higher "Fatigue" score. Fatigue derived from mobile phone use is likely to be mental fatigue, indicating that long periods of mobile phone use may serve as a chronic stressor that leads to depression. Indeed, chronic stress reportedly plays a role in the development of adolescent depression [14].

We also showed that increased hours of mobile phone use was associated with high scores for "Tension and excitement." Sakano et al. [9] stated that the subcomponent "Tension and excitement" enhances moods associated with the perception of a physical or physiological response to anxiety. In combination with our marginal result $(P$ for trend $=0.097$ ) for the association between mobile phone use and "Anxious mood," anxiety may be an underlying factor related to long periods of mobile phone use.

The subcomponent "Tension and excitement" includes five questions on irritability or restlessness (a high score indicates irritability) [9], and thus people who use mobile phones for longer periods of time may be more irritable. Irritability is an important indicator of adolescent depression [14]. Among our study population, total scores for "Tension and excitement" and "Depressed mood" were highly correlated, with a correlation coefficient $(r)$ of 0.722 $(P<0.001$, data not shown). These data also suggest that 
Table 5 Mean scores of Mood Inventory subcomponents according to overall quartiles of hours of mobile phone use per week stratified by Internet use

\begin{tabular}{|c|c|c|c|c|c|c|c|}
\hline \multirow{2}{*}{$\begin{array}{l}\text { Mood Inventory } \\
\text { subcomponents }\end{array}$} & \multicolumn{4}{|c|}{ Hours of mobile phone use per week } & \multirow{2}{*}{$\begin{array}{l}P \text { for } \\
\text { trend }^{\text {a }}\end{array}$} & \multirow{2}{*}{$\begin{array}{l}P \text { values }{ }^{\mathrm{b}} \\
(\text { ANCOVA) }\end{array}$} & \multirow{2}{*}{$\begin{array}{l}\text { Bonferroni's multiple } \\
\text { comparison }(P<0.05)\end{array}$} \\
\hline & $\begin{array}{l}\text { Quartile 1: } \\
<10 \mathrm{~h} / \text { week }\end{array}$ & $\begin{array}{l}\text { Quartile 2: } \\
\text { 10-18 h/week }\end{array}$ & $\begin{array}{l}\text { Quartile 3: } \\
\text { 19-32 h/week }\end{array}$ & $\begin{array}{l}\text { Quartile 4: } \\
\geq 33 \mathrm{~h} / \text { week }\end{array}$ & & & \\
\hline Internet users & $N=346$ & $N=422$ & $N=491$ & $N=508$ & & & \\
\hline $\begin{array}{r}\text { Tension and } \\
\text { excitement }\end{array}$ & $13.6(4.1)$ & $13.8(4.2)$ & $14.0(3.9)$ & $14.7(3.9)$ & $<0.001$ & $<0.002$ & $\begin{array}{l}\text { Quartile } 1 \text { vs. quartile } 4 \text {; } \\
\text { quartile } 2 \text { vs. quartile } 4\end{array}$ \\
\hline Refreshing mood & $13.7(2.7)$ & $14.1(3.0)$ & $13.9(2.7)$ & $13.8(2.7)$ & 0.407 & 0.274 & - \\
\hline Fatigue & $15.6(3.8)$ & $16.0(3.9)$ & $16.2(3.89$ & $16.7(4.0)$ & $<0.003$ & $<0.025$ & Quartile 1 vs. quartile 4 \\
\hline Depressed mood & $15.6(5.3)$ & $15.5(5.3)$ & $15.6(4.8)$ & $16.7(4.9)$ & $<0.022$ & $<0.007$ & $\begin{array}{l}\text { Quartile } 2 \text { vs. quartile } 4 \text {; } \\
\text { quartile } 3 \text { vs. quartile }\end{array}$ \\
\hline Anxious mood & $17.5(5.2)$ & $17.4(5.1)$ & $17.9(4.9)$ & $18.3(4.6)$ & $<0.023$ & 0.090 & - \\
\hline Internet non-users & $N=374$ & $N=198$ & $N=200$ & $N=135$ & & & \\
\hline $\begin{array}{r}\text { Tension and } \\
\text { excitement }\end{array}$ & $13.9(4.0)$ & $13.8(3.5)$ & $14.0(4.0)$ & $14.4(4.3)$ & 0.418 & 0.788 & - \\
\hline Refreshing mood & $14.0(2.8)$ & $13.7(2.7)$ & $14.1(3.0)$ & $14.3(2.9)$ & 0.454 & 0.302 & - \\
\hline Fatigue & $15.1(3.9)$ & $15.5(3.4)$ & $15.1(3.4)$ & $15.9(3.9)$ & 0.339 & 0.408 & - \\
\hline Depressed mood & $15.0(4.8)$ & $15.4(4.5)$ & $14.6(4.4)$ & $15.7(5.0)$ & 0.935 & 0.337 & - \\
\hline Anxious mood & $17.3(4.9)$ & $17.4(4.2)$ & $16.6(4.6)$ & $17.5(4.7)$ & 0.224 & 0.214 & - \\
\hline
\end{tabular}

Data are presented as the mean with the SD in parenthesis

a Tested by multiple regression analysis, adjusted for sex, school year, participation in sports club activities, mobile phone use experience, hours spent sleeping, and schools

b Tested by analysis of ANCOVA, adjusted for sex, school year, participation in sports club activities, mobile phone use experience, hours spent sleeping, and schools

people using mobile phones for long periods of time tend to be depressed.

We did not estimate the prevalence of depressed mood because the Mood Inventory does not provide a cutoff value for discriminating depression. Nonetheless, some researchers have reported the prevalence of depressed mood in Japanese high school students. Yamaguchi et al. [15] reported a prevalence of depressed mood of 30-33\% using a validated self-administered questionnaire (the Depression Self-Rating Scale for Children), Takakura et al. [16] reported a $53.4 \%$ prevalence for males and $61.4 \%$ prevalence for females using the Zung Self-rating Depression Scale, and Aiba et al. [17] reported a $63.4 \%$ prevalence for males and $64.2 \%$ prevalence for females using the Center for Epidemiological Studies-Depression Scale. The prevalence of depressed mood in high school students appears to be high, although prevalence rates depend on the scales and cutoff values used.

Depressed mood is a major symptom of mood disorders and depression according to the Diagnostic and Statistical Manual of Mental Disorders Fourth Edition [18], and thus long periods of mobile phone use potentially increase the risk of depression. Costello et al. [19] reported in their review article that the overall prevalence of depression in those aged 13-18 years was estimated to be $5.6 \%$. Yamaguchi et al. [15] estimated the prevalence of depression in
Japanese adolescents to be approximately $6 \%$. These prevalence rates in adolescents are as high as those reported in adults [20].

We demonstrated that mobile phone use for $\geq 21 \mathrm{~h}$ per 5 weekdays ( $\geq 4.2 \mathrm{~h}$ per day) was associated with increased "Depressed mood" (Table 3). Since the number of hours of mobile phone use was self-reported, measurement bias may have occurred. Despite this possibility, our study participants did use their mobile phones frequently even on weekdays, probably at both school and home. They primarily used mobile phones for email, with e-mail use reported by $94.4 \%$ of the participants, followed by $66.7 \%$ for telephone and $64.8 \%$ for Internet use. Our data are consistent with other reports on the hours of mobile phone use among Japanese high school students. The Japan Child and Family Research Institute [21] reported that $9.6 \%$ of high school students use e-mail or browse the Internet with a mobile phone for at least $4 \mathrm{~h}$ per day on weekdays. Watanabe et al. [22] reported that the median duration of use of mobile phones by high school students was $2.5 \mathrm{~h}$ per day (cf. 2.6 per day in 1 week and 2.0 per day on weekdays in our study). Despite discrepancies in the definition of mobile phone use among these studies, all studies found a long duration of mobile phone use among Japanese high school students.

There are several limitations to our study. First, the study used a cross-sectional design that does not 
necessarily imply causal relationships. In the context of this study, a depressed mood may be caused by long periods of mobile phone use in high school students, or alternatively, students with a depressed mood may spend more time using mobile phones. A longitudinal design is desirable to address this issue. Second, our study population was not randomly selected, but was accessible. Generalization of our results should be made with caution. Third, psychological effects of mobile phone use are characterized not only by duration, but also by frequency of use. Fourth, we evaluated psychological mood at one point in time, which may change. Finally, psychological mood is affected by a number of factors in daily life, such as medical history, menstruation, and disease under treatment, and the impact of its association with mobile phone use may be modified by unknown confounders that were not assessed in this study (e.g., personality, current relations to families and friends). These methodological limitations should be addressed in future studies.

To summarize, we found that high school students who use mobile phones for $>33 \mathrm{~h}$ per week ( $4.7 \mathrm{~h}$ per day) are at a high risk of having depressed mood, suggesting that increased duration of mobile phone use is associated with unfavorable psychological mood, particularly depression. Decreasing mobile phone use may be a useful strategy to maintain the mental health of adolescents, especially for very long-duration users. It should be noted, however, that some long-duration mobile phone users are addicted to their mobile phone and have poor social contact. These cases should be treated appropriately depending on the situation.

Acknowledgments We would like to thank the students of the seven high schools for their participation and the teachers for their assistance in data collection.

Conflict of interest None.

\section{References}

1. Ministry of Internal Affairs and Communications. White paper Information and Communications in Japan. Available at: http:// www.soumu.go.jp/johotsusintokei/statistics/statistics05.html.

2. Cabinet Office, Government of Japan. A child and a young-man white paper. Cabinet Office, Government of Japan, Tokyo; 2012.

3. Söderqvist F, Carlberg M, Hardell L. Use of wireless telephone and self-reported health symptoms: a population-based study among Swedish adolescents aged 15-19 years. Environ Health. 2008;7:18.

4. Khan MM. Adverse effects of excessive mobile phone use. Int J Occup Med Environ Health. 2008;21:289-93.

5. Tayama J. The relationship between mobile phone addiction and psycho- behavioral factors among high school students. Jpn J Psychosom Med. 2011;51:245-53 (in Japanese).
6. Yen CF, Tang TC, Yen JY, Lin HC, Huang CF, Liu SC, Ko CH. Symptoms of problematic cellular phone use, functional impairment and its association with depression among adolescents in Southern Taiwan. J Adolesc. 2009;32:863-73.

7. Kamibeppu K, Sugiura H. Impact of the mobile phone on junior high-school students' friendships in the Tokyo metropolitan area. Cyberpsychol Behav. 2005;8:121-30.

8. Sánchez-Martínez M, Otero A. Factors associated with cell phone use in adolescents in the community of Madrid (Spain). Cyberpsychol Behav. 2009;12:131-7.

9. Sakano Y, Fukui T, Kumano H, Horie H, Kawahara K, Yamamoto H, Nomura S, Suematsu H. Development and validation of a New Mood Inventory. Jpn J Psychosom Med. 1994; 34:629-36 (in Japanese).

10. Koivusilta LK, Lintonen TP, Rimpelä AH. Orientations in adolescent use of information and communication technology: a digital divide by sociodemographic background, educational career, and health. Scand J Public Health. 2007;35:95-103.

11. Augner C, Hacker GW. Associations between problematic mobile phone use and psychological parameters in young adults. Int J Public Health. 2012;57:437-41.

12. Lam LT, Peng ZW, Mai JC, Jing J. Factors associated with Internet addiction among adolescents. Cyberpsychol Behav. 2009;12:551-5.

13. Nishimura Y, Endo K. The relationships between text-message dependency, self-regulation, and alienation on Japanese high school students. Mem Hokuriku Gakuin Univ Hokuriku Gakuin Junior College 2010;3:157-68. (in Japanese).

14. Brent D, Weersing R. Depressive disorders in childhood and adolescence. In: Rutter M, Bishop D, Pine D, Scott S, Stevenson J, Taylor E, Thapar A, editors. Rutter's child and adolescent psychiatry. 5th ed. Malden: Blackwell Publishing; 2008.

15. Yamaguchi Y, Yamaguchi H, Harai H, Watanabe A, Tanaka $\mathrm{K}$, Syono M, et al. Three years longitudinal study of depressive group and estimated prevalence of depression in high school student. Jpn J Clin Psychiatry. 2009;38:209-18 (in Japanese).

16. Takakura M, Taira K, Shinya N, Miwa K. Prevalence of depressive symptoms and its relation to demographic variables in high school students. Nippon Koshueisei Zasshi. 1996;43:615-23 (in Japanese).

17. Aiba S, Kamibeppu K. Examination of depression and the factors involved in students of private high school: with focus on the impact of parental support. Jpn J Child Adolesc Psychiatry. 2010;51:21-30 (in Japanese).

18. American Psychiatric Association. Diagnostic and statistical manual of mental disorders, 4th edn. Washington D.C.: American Psychiatric Association; 1994.

19. Jane Costello E, Erkanli A, Angold A. Is there an epidemic of child or adolescent depression? J Child Psychol Psychiatry. 2006;47:1263-71.

20. Hasin DS, Goodwin RD, Stinson FS, Grant BF. Epidemiology of major depressive disorder: results from the National Epidemiologic Survey on Alcoholism and Related Conditions. Arch Gen Psychiatry. 2005;62:1097-106.

21. Japan Child and Family Research Institute (JCFRI). Almanac of data on Japanese children. Tokyo: Japan Child and Family Research Institute (JCFRI)/Chuoh Publishing Co.; 2013 (in Japanese).

22. Watanabe T, Isogai E, Tanaka E, Tomisaki E, Onda Y, Mochizuki $\mathrm{Y}$, et al. Implications of a safe internet environment for high school students: focus on the students' current internet usage and their empathy. Jpn J Child Health. 2012;71:38-45 (in Japanese). 